\title{
Organizational Characteristics and Disclosure Practices of Non-profit Organizations in Malaysia
}

\author{
Roshayani Arshad ${ }^{1}$, Noorbijan Abu Bakar ${ }^{1}$, Farah Haneem Sakri ${ }^{1}$ \& Normah Omar ${ }^{1}$ \\ ${ }^{1}$ Accounting Research Institute, Universiti Teknologi MARA, Malaysia \\ Correspondence: Roshayani Arshad, Accounting Research Institute, Faculty of Accountancy, Universiti \\ Teknologi MARA, 40450 Shah Alam, Malaysia. Tel: 60-13-322-3438. E-mail: roshayani@salam.uitm.edu.my
}

Received: July 31, 2012 Accepted: October 24, 2012 Online Published: December 31, 2012

doi:10.5539/ass.v9n1p209 URL: http://dx.doi.org/10.5539/ass.v9n1p209

\begin{abstract}
The purpose of this study is to examine the influence of organizational characteristics on the extent of disclosures in the annual reports of non-profit organizations (NPO) in Malaysia. Organizational characteristics and the extent of disclosures are obtained from the content analysis of annual reports of 213 NPOs registered with Registrar of Societies in Malaysia for the financial period 2010. This study provides evidence that the overall extent of disclosure is low. Of the organizational characteristics, this study revealed significant positive relationships between size and some types of funds available to the NPOs. The significant positive relationships between certain types of funds and extent of disclosures in some parts of the annual reports indicate selective disclosure strategies by non-profit managers, thus reducing meaningful transparency in the non-profit sector. Nevertheless, it indicates that non-profit managers are using disclosures in annual reports in managing their inter-organizational relationships in ensuring continuous flow of resources to their organisations.
\end{abstract}

Keywords: non-profit organizations, disclosures, size, resource dependence theory

\section{Introduction}

Non-profit organizations (NPOs) are characterized by their dependence on public donations, government funding and fees. According to resource dependence theory (RDT), an organization operating in this environment will survive if they can manage the flow of resources and reduces the uncertainty in their environment (Pfeffer \& Salancik, 1978). An important strategy in ensuring sustainability of the organization is to communicate relevant information to the current and future resource providers. Failure to communicate sufficient information can lead to negative perceptions regarding the organization's effectiveness in managing their resources and consequently lead to withdrawals of support by the donors and other stakeholders.

Provision of comprehensive information in annual reports of NPOs is an important mechanism in enhancing the credibility of the organization and public trusts. However, as NPOs are generally subjected to less stringent reporting requirements, the information reported can be insufficient as these organizations are less pressured to provide transparent information. In addition, the information disclosed is also subjected to a considerable discretion of the non-profit managers. For example, non-profit managers' disclosure incentives can be influenced by various motivations: to attract greater donations, market differentiation, public trusts and accountability. Such incentives can lead to varying level of comprehensiveness in the information disclosed in annual reports of the NPOs. In addition, it can also reduces the credibility and usefulness of the information disclosed to the various stakeholders. Hence, it is important to understand the factors that influence NPOs' decisions to voluntarily disclose or withhold disclosure of details about their activities and organisations (Gordon, Khumawala, Kraut \& Neely, 2010). Such understanding will provide useful insights into the factors that motivates disclosure decisions of non-profit managers and the effectiveness of voluntary disclosure regime within the non-profit sector domain.

The objective of this study is to examine the influence of organization characteristics on the extent of disclosures in annual reports of NPOs. Specifically, the extent of disclosure will be examined based on information disclosed in the balance sheets, statement of financial activities and notes to accounts. Such examination is expected to provide some insight into the potential motivations for transparency in annual reports of the NPOs and consequently contributes to the deliberations of enhancing transparency of NPOs by various regulatory authorities.

This paper will proceed by outlining the financial reporting requirements of NPOs in Malaysia. It will then 
review the literature on the relationships between organizational characteristics, and respectively, resource dependence theory and extent of disclosure, from which hypotheses will be developed. Finally, this paper will proceed to the empirical stage of variable measurement, sampling, data analysis, discussion of results, limitations and suggestions for future research.

\subsection{Financial Reporting Requirements of NPOs in Malaysia}

In Malaysia, NPOs comprised of organizations that are either charitable organizations or societies. NPOs with revenue of more than RM1 million can be registered as companies limited by guarantee and must be registered with the Companies Commission of Malaysia (CCM) and is held accountable by the Companies Act of 1965. For NPOs with revenue less than RM1 million, they must be registered with the Registrar of Societies Malaysia (ROS), within the Ministry of Home Affairs, and are held accountable by the Societies Act of 1966.

In relation to disclosure and reporting requirements, there is no specific accounting standard for the NPOs. Nevertheless, NPOs are encouraged to comply with the international financial reporting standards issued by International Accounting Standard Board and adopted by the Malaysian Accounting Standard Board or reporting standards applicable for private entities in the preparation and presentation of their financial statements. NPOs registered with ROS are required to submit Form 9 that consists of the statement of receipts and payments of the last financial year, together with a balance sheet showing the financial position of the last financial year to the ROS within sixty days after holding its annual general meeting. Other statements such as cash flow statement, statement of changes in general fund and notes, a summary of significant accounting policies and other explanatory notes are not required by the ROS. The overall disclosure and reporting requirements of NPOs in Malaysia reflect a minimum regulatory requirement environment.

\section{Literature Review and Generation of Hypotheses}

\subsection{Resource Dependence Theory, Organizational Characteristics and Disclosures}

The resource dependence theory (RDT) posits that the structure and behaviour of an organization can be explained by its resources (Pfeffer \& Salancik, 1978). The theory suggests that as an organization is unable to generate all the required resources for it to survive, it must depend on external resources. In other words, the organization must establish some relationships with other organizations or institutions because they need to acquire resources that are currently scarce within their own organization (Oliver, 1990; Thibault \& Harvey, 1997). A wide body of empirical research on disclosures in for-profit organizations highlights that disclosure in annual reports is an important mechanism for managers to communicate the activities and performance of their organizations to other organizations (Healy \& Palepu, 2001; Hossain \& Hammami, 2009). In this context, Latridis (2008) found that disclosure is required because managers are generally held responsible to meet certain business and financial targets.

Drawing on this literature, this study proposes that disclosure in annual reports of NPOs can be a useful mechanism in establishing inter-organizational relationships with other organizations or insitutions. The ability of an NPO to establish these relationships is expected to result in the flow of resources to the organization. For example, Trussel and Parsons (2008) find that certain characteristics of NPOs are associated with donation decisions. This in turn suggests that NPOs with certain characteristics are associated with more comprehensive disclosures of information in their annual reports in their efforts to manage their dependency relationships with the current and potential resource providers. This study focuses on two types of organizational characteristics: size and types of income of the organizations, and their influence on the extent of disclosures in annual reports of NPOs.

\subsection{Size and Extent of Disclosures}

Prior literature on disclosures in for-profit and NPOs has identified organizational size as an important capacity factor in determining the extent of disclosures (Saxton, Kuo \& Ho, 2011; Verbruggen, Christiaens \& Milis, 2011). Larger organizations are expected to have more capacity in the preparation and presentation of information in their annual reports. As such, it is generally expected that larger organizations are associated with more comprehensive disclosures in their annual reports. However, as an organization grows, it becomes more visible and is more likely to encounter greater scrutiny by regulatory authorities and other stakeholders (Luoma \& Goodstein, 1999). As such, larger organizations may be less motivated to disclose more comprehensive information in their annual reports.

In addition to the capacity factor, organizational size has been argued to be an important determinant of the extent of disclosures from a reputation perspective. This stream of literature (Trussel \& Parsons, 2008) argues that organizational growth can only be achieved when a non-profit entity is able to continue to generate revenues 
over a number of years. In other words, size may represent an organization's ability to attract revenues and contributions from external organizations and institutions. In generating these financial resources, it is important that an NPO communicate adequate information about their organizations and operations for potential resource providers to make informed donation decisions. Adequate information provides assurance to the donors that their donations will be used appropriately and that the organizations are legitimate and reputable NPOs. Based on these arguments, the following hypothesis is developed:

H1: The size of an NPO is significantly positively related to the extent of disclosures in annual reports.

\subsection{Funding Sources and Extent of Disclosures}

NPOs depend on funds contributed from various sources. Funds may be contributed by those external to the organizations, i.e. from various institutional donors as well as individual donors. In addition, NPOs may also generate funds through charging fees for services, membership fees, sales of assets and other funds generated activities. Irrespective of the source of funds, there is an increasing demand by donors that their donations are used for charitable purposes (Behn, DeVries \& Lin, 2010; Zainon, Atan, Wah \& Nam, 2011). Prior literature on NPOs suggests that donors are more likely to donate to organizations that provide adequate information about their organizations and activities (Hodge \& Piccolo, 2005; Saxton et. al, 2011). Hence, these literatures expect a positive relationship between the amount of funds and disclosure levels in annual reports of NPOs. However, as different categories of donors have different levels of knowledge, ability and experience in using the information disclosed for their donation decisions, it is expected that their influence on the disclosure strategy of the NPOs will vary accordingly. The literature on NPOs has generally categorized the funds of the NPOs into three categories: funds generated by specific activities such as membership fees and rental income, funds donated by external organizations, such as from the governments and other institutions, and finally, funds not generated from these two categories as funds from other activities.

NPOs generating large amount of funds from specific activities such as membership fees and rental income are more likely to be managed very similar to for-profit organizations (Froelich, 1999; Trussels \& Parson, 2008). As such, it is expected that the preparation and presentation of their annual reports will be those adopted by the for-profit organizations. In this regards, the non-profit managers are more likely to disclose more comprehensive information in their annual reports to signal that the organizations are managed efficiently for the appropriate charitable purposes. Hence, the following hypothesis is developed:

H2a: The amount of funds generated from NPOs' activities is significantly positively related to the extent of disclosures in annual reports.

Funds generated from donations can also be contributed from large institutional donors, such as government agencies and private institutions as well as small individual donors. Due to their large donations, institutional donors are more likely to demand higher disclosure levels for monitoring purposes. In contrast, the small individual donors are expected to be less sophisticated in relation to their knowledge, ability and experience in understanding the financial statements of the NPOs and as a consequent are less likely to demand higher disclosure levels. Nevertheless, the presence of large donations from institutional donors can also give assurance to smaller individual donors that such NPOs are credible and reputable organizations. This in turn will also increases funding from smaller donors. Overall, NPOs with larger proportion of funds from institutional donors are more likely to disclose more comprehensive disclosure in their annual reports to signal their credibility and reputation as legitimate NPOs. Following this argument, the following hypothesis is developed:

$\mathrm{H} 2 \mathrm{~b}$ : The amount of funds generated from donations is significantly positively related to the extent of disclosures in annual reports.

In this study, the amount of funds not generated from the above two types of funds are classified as funds generated from other activities. While past literature has provided inconclusive evidence (Parsons, 2007) on the relationships between this category of funds and disclosure levels, this study expects a positive relationship between funds generated from other activities and disclosure levels. This is based on the premise that donors demand adequate information to make their donation decisions even though donors may not always have access to financial statements submitted by the NPOs to the regulatory authorities. Nevertheless, the increasing calls for transparency in the non-profit sector indicate that donors need some information that can provide assurance regarding the NPOs reputation and legitimacy. This leads to the following hypothesis:

$\mathrm{H} 2 \mathrm{c}$ : The amount of funds generated from other activities is significantly positively related to the extent of disclosures in annual reports. 


\section{Methods}

\subsection{Sample and Data Collection}

The sample consists of 213 societies registered with the Registrar of Societies (ROS) for the financial year 2010. The research approach involves the content analysis of societies' annual reports. Content analysis has been widely employed in prior studies to measure voluntary and mandatory disclosures in annual reports (Hackston \& Milne, 1996; O'Donovan, 2002; Clemens \& Douglas, 2006).

\subsubsection{Extent of Disclosure}

The extent of disclosures in annual reports of societies in this study is measured based on a self-constructed index. The identification of items to be included in the index is guided by the review of prior studies relevant to disclosures in annual reports of NPOs (Beck, Campbell \& Shrives, 2010; Molina-Azorin, Claver-Cortes, Lopez-Gamero \& Tari, 2009), mandatory disclosures as required by the Societies Act 1966 and recommended practices in other countries. In Malaysia, there are no particular regulatory requirements in relation to financial reporting practices for NPOs registered with ROS, except for brief requirements on the need to prepare and submit the balance sheets and statement for revenue and expenditure by the Society Act 1966. As such, the identification of such practices is also guided by a review of best practices adopted by countries with compliant status "Largely Compliant or LC" based on Asia Pacific Group (APG) Mutual Evaluation 2007 report. Malaysia became member of the APG on 31 Mei 2000 and as a consequence, NPOs are required to disclose certain information in relation to governance in their annual reports. Malaysia and other member countries of the APG are required to implement and comply with certain recommendations on anti-money laundering and terrorism financing. Failure to comply can cause a member country to be blacklisted and subject to various sanctions e.g. economy sanction, trade restriction, higher level of scrutiny, etc. Based on the 2007 audit by the APG, Malaysia scored partial compliance. It is expected that member countries with largely compliance scores are also associated with more comprehensive disclosures in their annual reports. Of relevance to this study, best practices in Singapore, New Zealand and United Kingdom are reviewed. Based on the review of relevant literatures and recommended practices, a list of items to be included under financial reporting practices disclosures is identified. This is followed by discussions with several officials from ROS in order to get insights into the types of information required by ROS for effective monitoring of societies.

Finally, once the disclosure items have been identified, a pilot study of content analysis of annual reports of societies for the year ending 31 December 2010 was carried out. A sample of 20 societies was selected at random for the pilot study. A list of disclosure items disclosed in the annual reports of these societies are extracted and compared against the categories and disclosure items included in the developed disclosure index. Based on this preliminary content analysis, a review of the categories and disclosure items was made and minor modifications were made to the items of disclosure. The final disclosure index contains 60 disclosure items.

A summary of the items listed in the Disclosure Index (DI) is shown in Table 1.

Table 1. Summary of items listed in DI

\begin{tabular}{lc}
\hline Extent of Disclosures & Number of Items \\
\hline Balance Sheets (18 items) & 2 \\
Non-Current Assets & 6 \\
Current Assets & 3 \\
Current Liabilities & 4 \\
Non-Current Liabilities & 3 \\
Society's Funds & \\
Statement of Financial Activities (19 items) & 4 \\
Funds Generated from Activities & 4 \\
Funds from Donations & 2 \\
Other Income & 9 \\
Operating Expenses & 9 \\
Notes to Accounts (23 items) & \\
Balance Sheets Items & 7 \\
Statement of Financial Activities Items & 7 \\
Others & 9 \\
Total & 60 \\
\hline
\end{tabular}


For each society, the extent of disclosure is assessed using an equal-weighted index, where a point is awarded for each item of information disclosed. Disclosure score for each society is totalled and not given any specific percentage as it is considered that each item of disclosure is equally important. This scoring approach is also consistent with prior studies on disclosures in for-profit organizations (Chau \& Gray, 2002; Haniffa \& Cooke, 2002). The extent of DI for each society $j$ is constructed as follows:

$$
\mathrm{DI}=\sum_{i=1}^{m_{j}} \frac{d_{j}}{N}
$$

Where $N=$ number if items expected for $\mathrm{j}^{\text {th }}$ society, $N \leq 60$

$d_{j}=0$ to 3 as per rating in Table 2

The index indicates the extent of disclosure for a society $j$, where $N$ is the maximum number of relevant items a society may disclose and $d_{i}$ is equal to 0 to 3 points as indicated in Table 2, where the minimum score is zero and the maximum score is 3 . The total maximum scores for a company $m j$ is 180 (60 items $\mathrm{x} 3$ points) while a minimum score can be zero.

Table 2. Rating points for items listed in DI

\begin{tabular}{ll}
\hline Scores & Descriptions \\
\hline 0 & Not Disclosed \\
1 & Disclosed with qualitative information only \\
2 & Disclosed with qualitative and/or quantitative information \\
3 & Disclosed with detailed information, contains both qualitative and quantitative information \\
\hline
\end{tabular}

\subsection{Measurement of Variables}

There are four independent variables in this study, organizational size, funds generated by NPO, funds from donations and funds generated from other activities. The definition and measurement of variables used in this study are listed in Table 3.

Table 3. Measurement of independent variables

\begin{tabular}{|c|c|c|}
\hline Variable & Definition & Measurement \\
\hline Size & Size of organization. & Total assets. \\
\hline GF & $\begin{array}{l}\text { Funds generated by NPO (e.g. } \\
\text { Subscriptions fees) }\end{array}$ & Total income from generated fund. \\
\hline FD & Funds from donations & Total income from donations. \\
\hline $\mathrm{FO}$ & Funds from other activities (e.g. rental) & Total income from other activities. \\
\hline
\end{tabular}

\subsection{Limitations of Study}

This study has some limitations with regards to the empirical modeling and variable measurement. First, the empirical modeling does not include other organizational characteristics, such as board composition and types of auditors that could have an impact on the extent of disclosures in the annual reports. Second, non-disclosure of some items in the annual reports may not be applicable to some NPOs as there are no specific framework to guide the NPOs registered with ROS in preparing and reporting their annual reports.

\section{Results and Discussion}

\subsection{Descriptive Statistics}

Table 4 presents the descriptive statistics on the dependent variable, DI. The results of descriptive statistics for continuous independent variables and control variable are presented in Table 5.

Table 4. Descriptive statistics for dependent variables

\begin{tabular}{lcccc}
\hline & Label & Min & Max & Mean \\
\hline Total extent of disclosure & DI (\%) & 0.00 & 49.00 & 12.00 \\
Extent of disclosure - balance sheets & BS (\%) & 0.00 & 47.00 & 11.00 \\
Extent of disclosure - statement of activities & IS (\%) & 0.00 & 57.00 & 16.00 \\
Extent of disclosure - notes to accounts & NOTES (\%) & 0.00 & 61.00 & 10.00 \\
\hline
\end{tabular}


Table 4 reported that the overall extent of disclosures is very low. The mean value for the overall extent of disclosure is $12 \%$. Further analyses also reveal that the mean values for the extent of disclosures in the balance sheets, statement of activities and notes to accounts are $11 \%, 16 \%$ and $10 \%$ respectively. It is interesting to note that the minimum values for the extent of disclosures in each of these statements are zero. This indicates that some NPOs in the sample of study did not provide any information with regards to either one of these statements. The maximum values for all the statements are moderately high, with the highest maximum value of $61 \%$ reported for the extent of disclosure in the notes to accounts.

Table 5. Descriptive statistics for independent variables

\begin{tabular}{lcccc}
\hline & Label & Min & Max & Mean \\
\hline Size of organization & SIZE (RM) & 0.00 & $17,904,924.00$ & $635,587.00$ \\
Funds generated by NPOs & GF (RM) & 0.00 & $7,151,654.00$ & $208,331.00$ \\
Funds from donations & FD (RM) & 0.00 & $8,558,171.00$ & $115,894.00$ \\
Funds from other activities & FO (RM) & 0.00 & $9,057,225.00$ & $341,059.00$ \\
\hline
\end{tabular}

Table 5 reported that the mean value for size, based on value of assets, is RM635,587.00. While Table 5 reported that some NPOs in the sample has no asset, others are relatively large with a maximum value of RM17,904, 924.00. In relation to funds, the minimum values reported from various sources are zero. The maximum values reported for all these funds range from RM7,151,654.00 to RM9,057,225.00 while the mean values range from RM115,894.00 to RM341,059.00.

\subsection{Multivariate Analysis}

In this study, linear multiple regression is used as the basis of analysis for testing all the hypotheses. The hypothesized relationships are modeled as follows.

Model 1:

$$
\mathrm{DI}=\beta_{0}+\beta_{1} \mathrm{SIZE}+\beta_{2} \mathrm{GF}+\beta_{3} \mathrm{FD}+\beta_{4} \mathrm{FO}+\varepsilon_{\mathrm{t}}
$$

Sub-analyses of the above relationships based on the extent of disclosures in various types of statements are based on the following models:

Model 2:

$$
\mathrm{BS}=\beta_{0}+\beta_{1} \mathrm{SIZE}+\beta_{2} \mathrm{GF}+\beta_{3} \mathrm{FD}+\beta_{4} \mathrm{FO}+\varepsilon_{\mathrm{t}}
$$

Model 3:

$$
\mathrm{IS}=\beta_{0}+\beta_{1} \mathrm{SIZE}+\beta_{2} \mathrm{GF}+\beta_{3} \mathrm{FD}+\beta_{4} \mathrm{FO}+\varepsilon_{\mathrm{t}}
$$

Model 4:

$$
\text { NOTES }=\beta_{0}+\beta_{1} \mathrm{SIZE}+\beta_{2} \mathrm{GF}+\beta_{3} \mathrm{FD}+\beta_{4} \mathrm{FO}+\varepsilon_{\mathrm{t}}
$$

where variable definitions are given in Table 3 .

In the above regression models, multicollinearity was tested using the variance inflation factor and tolerance

\begin{tabular}{|c|c|c|c|c|c|c|c|c|}
\hline Dependent Variable & \multicolumn{2}{|c|}{ DI } & \multicolumn{2}{|c|}{ BS } & \multicolumn{2}{|c|}{ IS } & \multicolumn{2}{|c|}{ NOTES } \\
\hline R Square & \multicolumn{2}{|c|}{0.732} & \multicolumn{2}{|c|}{0.777} & \multicolumn{2}{|c|}{0.566} & \multicolumn{2}{|c|}{0.476} \\
\hline Adjusted R Square & \multicolumn{2}{|c|}{0.725} & \multicolumn{2}{|c|}{0.772} & \multicolumn{2}{|c|}{0.555} & \multicolumn{2}{|c|}{0.464} \\
\hline F Statistic & \multicolumn{2}{|c|}{112.87} & \multicolumn{2}{|c|}{144.36} & \multicolumn{2}{|c|}{53.92} & \multicolumn{2}{|c|}{37.63} \\
\hline Sig. & \multicolumn{2}{|c|}{0.000} & \multicolumn{2}{|c|}{0.000} & \multicolumn{2}{|c|}{0.000} & \multicolumn{2}{|c|}{0.000} \\
\hline & $\mathrm{t}$ & Sig. & $\mathrm{t}$ & Sig. & $\mathrm{t}$ & Sig. & $\mathrm{t}$ & Sig. \\
\hline Constant & -0.623 & 0.534 & 0.204 & 0.839 & -0.508 & 0.612 & 1.360 & 0.175 \\
\hline SIZE & 11.733 & $0.000 * * *$ & 19.062 & $0.000 * * *$ & 4.310 & $0.000 * * *$ & 7.229 & $0.000 * * *$ \\
\hline GF & 3.162 & $0.002 * * *$ & 0.669 & 0.504 & 3.754 & $0.000 * * *$ & 1.930 & $0.055^{*}$ \\
\hline FD & 2.348 & $0.020 * *$ & -1.277 & 0.203 & 4.431 & $0.000 * * *$ & 0.948 & -0.344 \\
\hline FO & 1.174 & 0.242 & -0.775 & 0.439 & 1.548 & 0.123 & 0.253 & 0.801 \\
\hline
\end{tabular}
levels, and found to be well within the satisfactory range. The results of the regression analysis are presented in Table 6 and are now discussed in terms of tests of each of the hypotheses.

Table 6. Multiple regression results for factors affecting the extent of disclosures 
Coefficient for each variable is shown with $\mathrm{t}$ values in parentheses. ${ }^{*}$ Significant at 10 per cent level (1-tailed test); $* *$ Significant at 5 per cent level (1-tailed test);*** Significant at 1 per cent level (1-tailed test)

Results of the multiple regression analysis in Table 6 report that the adjusted $\mathrm{R}^{2}$ is 0.725 where the dependent variable is the overall extent of disclosure (DI). H1 predicts that SIZE is significantly positively related to DI. The results in Table 6 reveal a significant relationship. Hence, HI is accepted. From a RDT perspective, these results suggest that larger organizations are using disclosures in annual reports as a communication mechanism as part of their dependency relationship management strategy with the current and potential resource providers. Effective management of inter-organizational relationships is important in ensuring continuous flow of financial and other resources to the NPOs. The significant relationships between SIZE and extent of disclosures in this study infer that comprehensive disclosures in annual reports are paramount in effective management of inter-organizational relationships.

From a capacity factor perspective, larger organizations are expected to have the capacity with regards to the preparation and presentation of their annual reports. Hence, they are more motivated to disclose more comprehensively in their annual reports. This is corroborated by the significant relationships between SIZE and extent of disclosures in the BS, IS and NOTES. In addition, these results indicate that larger NPOs are disclosing more information on a voluntary basis as there is very little reporting requirements for NPOs registered with ROS in Malaysia. The literature on disclosures for-profit organisations operating in the Asia Pacific region suggests that reporting practices promoted by regulatory authorities are more likely to succeed in coercing organisations to provide more comprehensive disclosures in their annual reports (Saxton et al., 2011). As such, it is expected that the extent of disclosures in annual reports of NPOs will increase with the presence of reporting guidance promoted by the relevant authorities.

H2a predicts that the amount of funds generated from NPOs' activities is significantly positively related to the extent of disclosures in annual reports. Table 6 reported that GF is significantly positively related to DI. Hence, $\mathrm{H} 2$ is accepted. These results suggest that these organizations are more likely to be managed as for-profit organizations (Trussels \& Parson, 2008). The focus on generating funds to their organizations provides a possible explanation for the significant and positive relationships between GF and the extent of disclosure in the statement of financial activities (IS). In contrast, GF is not significantly related to the extent of disclosures in the balance sheets (BS). However, the significant relationship between GF and the extent of disclosures in the notes to accounts (NOTES) suggest that the non-profit managers are motivated to disclose certain information in their annual reports to signal that the organizations are managed efficiently for the appropriate charitable purposes. This in turn is expected to result in continuous support by the various stakeholders for the activities engaged by the NPOs to generate funds. The selective disclosure strategy revealed in this study provides further support that the presence of reporting requirements promoted by the relevant authorities can be a mechanism to promote transparency in the non-profit sector.

With regards to funds generated from donations, H2b predicts that the amount of funds generated from donations is significantly positively related to the extent of disclosures in annual reports. Table 6 reported significant and positive relationships between FD and DI. Hence, H2b is accepted. However, results based on the extent of disclosures in other statements revealed that FD is only significantly positively related with IS. A possible explanation is that NPOs consider information in the statement of activities is sufficient to fulfill the donation decisions of their donors. Consistent with results of a pilot study on information needs by institutional donors in Malaysia by Zainon et al. (2011), donors are concerned with certain types of information in the annual reports of the NPOs. In addition, results in Table 6 also suggest that the proportion of institutional donors in the sample of study is higher as it is expected that these donors are more likely to demand higher disclosure levels due to their knowledge, ability and experience in understanding the financial statements of the NPOs relative to other donors.

$\mathrm{H} 2 \mathrm{c}$ predicts that the amount of funds generated from other activities is significantly positively related to the extent of disclosures in annual reports. However, results in Table 6 revealed insignificant relationships between FO and DI as well as the extent of disclosures in BS, IS and NOTES. Hence, H2c is rejected. These results suggest that NPOs with larger proportion of funds generated from other activities are not motivated to provide sufficient information to current or potential donors and to other stakeholders. It is possible that these NPOs are providing very minimal information as required by the current reporting requirements.

\section{Conclusion and Limitations}

This study examines the relationships between organizational characteristics of NPOs and the extent of disclosures in their annual reports. The significant positive relationships between size and some types of funds indicate that non-profit managers are using disclosures in annual reports in managing their inter-organizational 
relationships in ensuring continuous flow of financial and other resources to their organisations. In addition, the significant relationships between size and the extent of disclosures in various statements of the annual reports indicate that smaller NPOs need some guidance with regards to the preparation and presentation of their annual reports. Reporting guidance or best practices promoted by regulatory authorities are expected to enhance the transparency of annual reports prepared by smaller NPOs.

The significant positive relationships between certain types of funds and extent of disclosures in some parts of the annual reports indicate selective disclosure strategies by non-profit managers. In other words, NPOs are selecting the information they are willing to communicate to the donors and other stakeholders. In this context, NPOs are more likely to focus on information needs of larger donors. Such information may not fulfil the needs of smaller donors and other stakeholders. These results further indicate the importance of reporting requirements or best practices promoted by the relevant authorities in enhancing meaningful transparency in the non-profit sector.

Overall, the results in this study provide new evidence regarding the current disclosure practices in annual reports as well as the factors influencing the disclosure strategies of non-profit managers. Such findings can be used as a guide in developing the appropriate framework and best practices that can be used to facilitate the preparation and presentation of societies' annual reports. This in turn can enhance the regulators' commitment and effectiveness in regulating and monitoring the NPOs. Overall, the findings provide useful information to regulators in their continuous efforts to improve transparency and accountability in the non-profit sector. Given the centrality of transparency in the context of non-profit accountability, future research can examine other determinants of transparency. Future research can also conduct interviews or surveys in establishing the relevance of specific items of disclosures for each society.

\section{Acknowledgements}

This research has been funded by Accounting Research Institute Grant, Ministry of Higher Education, Malaysia

\section{References}

Beck, A. C., Campbell, D., \& Shrives, P. J. (2010). Content Analysis in Environmental Reporting Research: Enrichment and Rehearsal of the Method in a British-German Context. The British Accounting Review, 42, 207-222. http://dx.doi.org/10.1016/j.bar.2010.05.002

Behn, B. K., DeVries, D. D., \& Lin, J. (2010). The Determinants of Transparency in Non-profit Organizations: An Exploratory Study. Advances in Accounting, incorporating Advances in International Accounting, 26, 6-12. http://dx.doi.org/10.1016/j.adiac.2009.12.001

Chau, G. K., \& Gray, S. J. (2002). Ownership Structure and Corporate Voluntary Disclosure in Hong Kong and Singapore. The International Journal of Accounting, 37(2), 247-265. http://dx.doi.org/10.1016/S0020-7063(02)00153-X

Clemens, B., \& Douglas, T. J. (2006). Does coercion drive firms to adopt Voluntary' green initiatives? Relationships among coercion, superior firm resources, and voluntary green initiatives. Journal of Business Research, 59, 483-491. http://dx.doi.org/10.1016/j.jbusres.2005.09.016

Froelich, K. A. (1999). Diversification of Revenue Strategies: Evolving Resource Dependence in Non-profit Organizations. Nonprofit and Voluntary Sector Quarterly, 28(3), 246-268. http://dx.doi.org/10.1177/0899764099283002

Gordon, T. P., Khumawala, S. B., Kraut, M., \& Neely, D. G. (2010). Five Dimensions of Effectiveness for Non-profit Annual Reports. Nonprofit Management \& Leadership, 21(2), 209-228. http://dx.doi.org/10.1002/nml.20021

Hackston, D., \& Milne, M. J. (1996). Some Determinant of Social and Environment in New Zealand Companies. $\begin{array}{llll}\text { Accounting, Auditing \& Accountability Journal, } & 9(1), \quad 77-108 .\end{array}$ http://dx.doi.org/10.1108/09513579610109987

Haniffa, R. M., \& Cooke, T. E. (2002). Culture, Corporate Governance and Disclosure in Malaysia Corporations. Abacus, 38(3), 317-349. http://dx.doi.org/10.1111/1467-6281.00112

Healy, P. M., \& Palepu, K. G. (2001). Information Asymmetry, Corporate Disclosure, and the Capital Markets: A Review of the Empirical Disclosure Literature. Journal of Accounting and Economics, 31, 405-440. http://dx.doi.org/10.1016/S0165-4101(01)00018-0 
Hodge, M. M., \& Piccolo, R. F. (2005). Funding Source, Board Involvement Techniques, and Financial Vulnerability in Nonprofit Organizations: A Test of Resource Dependence. Nonprofit Management \& Leadership, 16(2), 295-315. http://dx.doi.org/10.1002/nml.99

Hossain, M., \& Hammami, H. (2009). Voluntary Disclosure in the Annual Reports of an Emerging Country: The Case of Qatar. Advances in Accounting, Incorporating Advances in International Accounting, 25, 255-265. http://dx.doi.org/10.1016/j.adiac.2009.08.002

Latridis, G. (2008). Accounting Disclosure and Firms' Financial Attributes: Evidence from the UK Stock Market. International Review of Financial Analysis, 17(2), 219-241. http://dx.doi.org/10.1016/j.irfa.2006.05.003

Luoma, P., \& Goodstein, J. (1999). Stakeholders and Corporate Boards: Institutional Influences on Board Composition and Structure. Academy of Management Journal, 42, 553-563. http://dx.doi.org/10.2307/256976

Molina-Azorin, J. F., Claver-Cortes, E., Lopez-Gamero, M. D., \& Tari, J. J. (2009). Green Management and Financial Performance: A Literature Review. Management Decision, 47(7), 1080-1100. http://dx.doi.org/10.1108/00251740910978313

O'Donovan, G. (2002). Environmental Disclosures in the Annual Report: Extending the Applicability and Predictive Power of Legitimacy Theory. Accounting, Auditing \& Accountability Journal, 15(3), 344-372. http://dx.doi.org/10.1108/09513570210435870

Oliver, C. (1990). Determinants of Inter-Organizational Relationships: Integration and Figure Directions. The Academy of Management Review, 15(2), 241-265.

Parsons, L. M. (2007). The Impact of Financial Information and Voluntary Disclosure on Contributions to Not-For-Profit Organizations. Behavioral Research in Accounting, 19, 179-196. http://dx.doi.org/10.2308/bria.2007.19.1.179

Pfeffer, J., \& Salancik, G. R. (1978). The External Control of Organizations: A Resource Dependence Perspective. Upper Saddle River: Pearson Education.

Saxton, G. D., Kuo, J.-S., \& Ho, Y.-C. (2011). The Determinants of Voluntary Financial Disclosure by Non-profit Organizations. Nonprofit and Voluntary Sector Quarterly, $x x(\mathrm{x}), 1-21$.

Thibault, L., \& Harvey, J. (1997). Fostering Interorganizational Linakges in the Canadian Sport Delivery System. Journal of Sport Management, 11, 45-68.

Trussel, J. M., \& Parsons, L. M. (2008). Financial Reporting Factors Affecting Donations to Charitable Organizations. Advances in Accounting, 23, 263-285. http://dx.doi.org/10.1016/S0882-6110(07)23010-X

Verbruggen, S., Christiaens, J., \& Milis, K. (2011). Can Resource Dependence and Coercive Isomorphism Explain Non-profit Organizations' Compliance With Reporting Standards? Nonprofit and Voluntary Sector Quarterly, 40(1), 5-32. http://dx.doi.org/10.1177/0899764009355061

Zainon, S., Atan, R., Wah, Y. B., \& Nam, R. Y. T. (2011). Institutional Donors' Expectation of Information from the Non-Profit Organizations (NPOs) Reporting: A Pilot Survey. International NGO Journal, 6(8), 170-180. 